\title{
Disparities between Schools in Japanese Compulsory Educa- tion: Analyses of a Cohort Using TIMSS 2007 and 2011
}

\author{
Matsuoka, Ryoji*
}

\begin{abstract}
Japanese compulsory education had been praised because of its equality around the early 80's. However, since the third wave-educational reform that began in the 1980s and still persists, it has been pointed out that there are disparities between schools in terms of students' socioeconomic background and academic performance. Although there have been studies assessing relationships between students' family background and academic ability between types of schools (e.g., private and public), how the disparities emerge between schools has not been investigated with nationally representative data collected in Japan. This study therefore attempts to empirically provide evidence of disparities between schools in elementary and lower secondary education by analyzing an age cohort at two points of time.

Using fourth grade data from The Trends in International Mathematics and Science Study (TIMSS) 2007 and eighth grade data from TIMSS 2011, the study first assesses (1) whether a school-composition of students' cultural capital (school-CC) shapes teachers' expectations for student achievement and (2) whether teachers' expectations relate to their teaching approach, which is measured as the frequency of homework assignments given to their students. After these two relationships are tested at the school level, the study investigates, through a multilevel regression analysis, (3) whether teachers' expectations and teaching approach are associated with students' academic performance in mathematics so as to reveal how school-CC-disparities relate to the achievement gap between schools. Findings of this study indicate disparities between schools in terms of school-CC, the degree of teachers' expectations, the frequency of homework assignments and math-achievement in eighth grade, while some disparities between schools are found at the fourth grade level. The findings also show that teachers' expectations are associated with eighth grade students' academic performance; that is, the degree of teachers' expectations partly explains the achievement gap between schools.
\end{abstract}

Keywords: Compulsory education; achievement gap; teachers' expectations; multilevel modeling; TIMSS

* Survey Research Center, The Institute of Statistical Mathematics, Research Organization of Information and Systems

e-mail: ryoji.matsuoka@gmail.com 


\section{Introduction}

Disparities between schools in compulsory education have been well-documented in the United States where most students go to neighboring public schools that are mainly financed by local property taxes. There is a severe socioeconomic inequality between and within school districts in terms of student demographics (i.e., socioeconomic and racial composition) and school-finance level, which are known to contribute to the achievement gap (e.g., Condron \& Roscigno, 2003; Kozol, 1991, 2005). In contrast, Japanese compulsory education had been praised because of its equality around the early 80's (e.g., Cummings, 1980). In fact, disparities between regions in Japanese compulsory education were viewed as a social problem in the postwar period, and a standardization of education took place (e.g., progressive investment in education: more public expenditures per pupil in poor prefectures); the relationship between wealth and academic performance at the prefectural level therefore nearly disappeared (Kariya, 2009). While strengths of Japanese compulsory education (e.g., lesson study and teachers' cooperation) have been pointed out in comparative studies (e.g., Lewis, 1995; Stigler \& Hiebert, 1999; Tsuneyoshi 2001), inequality in educational attainment has been increasingly highlighted in the literature; there is not only an achievement gap based on socioeconomic status (SES), but there also exist social-class differences between students in terms of attitudes, perceptions and motivation toward education (Kariya, 2013).

In addition to the disparities between individual students, between-school disparities have received more attention since the third wave of educational reforms based on market fundamentalism that began in the 1980s and still persists (Fujita 2010). Specifically, a "rich flight" phenomenon coined by Fujita (2010) can be observed in the Tokyo metropolitan area; families of middle- and upper-class tend to send their children to private schools, schools attached to national universities, schools with unified lower and upper secondary education programs, and popular schools through the school choice system. Studies that focus on parental involvement in education (e.g., Kataoka, 2009; Mochizuki, 2011) also indicate that children who apply for private elementary and junior high schools are from high SES families. Analyses of Trends in International Mathematics and Science Study (TIMSS) 2003 show that as a consequence of private schooling, junior high school students attending private schools located in urban areas demonstrate relatively higher academic performance, which is more than predicted based on students' SES; there is a possibility that private junior high schools in urban areas contribute to widening the achievement gap (Taki, 2012). This issue deserves to be investigated further. In fact, recently students who attend top-private high schools are much more likely to gain admission to competitive universities; since most top private schools have unified lower secondary education programs and students need to prepare for entrance examinations for such schools, the SES-based inequality gap would widen due to this early selection process (Kariya, 2011).

Overall, the literature suggests that there exist SES-based inequality and achievement gaps even at the level of compulsory education. ${ }^{1}$ These studies, however, tend to focus almost exclusively on differences between individuals and between school sectors (i.e., public schools, compared with private counterparts), even though most students in compulsory education attend neighborhood public schools, and there are likely to be SES-based disparities between public schools depending on the region. This study therefore attempts to empirically investigate between-school disparities by using multilevel modeling techniques, while controlling for the types of school sectors. 


\section{Studies on how disparities between schools emerge and persist}

Studies that address between-school/classroom differences in Japan have revealed an achievement gap between schools (e.g., Kawaguchi, 2009), characteristics of effective schools in Japanese society (e.g., Shimizu, 2009), classroom-effects on students' achievement (Yamada, 2009), and a relationship between teaching methods and academic performance (e.g., Sudo, 2013). While these studies mainly test relationships between specific school factors (e.g., teaching methods) and students' test scores by controlling for student- and/or school- SES, they do not assess whether school factors differ by school-SES: the SES context in which schools are embedded. A study by Nishimoto (2001) is an exception in this regard. Using regional data of elementary and junior high school students in Japan, he contends that students' social class differentiates teachers' evaluation of students, which then influences students' academic performance with independent student-SES effect. This area of study has been well-documented outside of Japan; U.S. studies show that the degree of teachers' expectations toward student achievement differs depending on students' SES, differentiating teachers' teaching method/ approach, which in turn contributes to the achievement gap. More concretely, Rist (1977) applies labeling theory that explains deviated behaviors to education. Building on empirical studies at the time, he discusses that teachers "label", or make assumptions about students based on social class, race, gender, previous academic results, physical appearance and so forth. This determines a certain level of expectations for student achievement, leading teachers to differentiate their teaching methods, which then relates to students' actual academic performance; such labeling leads to self-fulfilling prophecies. Studies in tracking/ability grouping (e.g., Oakes, 1985) also indicate differences in students' backgrounds, teachers' expectations for student achievement, different instructional approaches, and students' academic gains between tracks or ability groupings. Additionally, studies that examine effects of school characteristics on student learning (e.g., Lee \& Loeb, 2000) suggest that expectations held by teachers at the school level, which is often referred to as teachers' attitudes about collective responsibility for student learning, influence student achievement. Relatively recent studies have indicated that teachers' evaluation of student academic ability differs not only due to individual students' SES but also as a group--the averaged SES in class (a SES composition) (e.g., Ready \& Wright 2011). Moreover, teachers' expectations in first grade have a long term effect on students, especially those in poverty (Sorhagen 2013). In summary, the literature suggests that teachers' expectations vary by students' individual SES and school-SES composition, which is likely shaped by institutional arrangements (i.e., tracking and ability grouping) and could very well influence student learning.

\section{Research questions and hypotheses}

It is crucial to investigate disparities between schools in compulsory education because most students attend neighborhood public schools, and many of them have no other choice. Despite the importance of examining between-school disparities and clarifying how the achievement gap between schools emerges and widens, it has not been assessed with nationally representative data collected in Japan. This study therefore attempts to provide empirical evidence of SES disparities between schools, while controlling for types of schools (e.g., 
private/public classifications). More specifically, the study will investigate how the SES-disparities between schools relate to specific school factors (i.e., teachers' expectations for student achievement and teaching approach) that are also associated with student achievement, in order to uncover how the achievement gap between schools emerges and widens in Japanese compulsory education. For these purposes, the first two research questions of this study are; (1) does a school-socioeconomic indicator shape teachers' expectations for student achievement?, and (2) is the degree of the expectations for student achievement associated with teachers' teaching approach? After these are tested, the study assesses the third research question; (3) do school-factors explain the achievement gap between schools? In addition to these inquiries, to clarify when such disparities may emerge and widen, a final question of the study is; (4) do disparities between schools become wider from elementary to lower secondary education? To examine this question, the study will analyze the same cohort at two points of time: fourth- and eighth- grade levels.

Hypothesis 1: School socioeconomic factor influences the degree of teachers' expectations for student achievement.

As classroom-SES is purportedly related to teachers' evaluations of students (Ready \& Wright 2011) and the same tendency is observed in tracking/ability grouping studies, it is expected that school socioeconomic factors will shape the degree of teachers' expectations for student achievement. Teachers at schools with a higher socioeconomic composition of students will tend to have a higher degree of expectations for student achievement.

Hypothesis 2: The degree of teachers' expectations for student achievement differentiates teachers' teaching approach.

Building on the study by Yamada (2009) that uses the frequency of homework assignments reported by teachers as a classroom-factor in his analyses, this study treats the frequency of homework assignments in mathematics as teachers' instructional approach. If teachers label students based on students' SES and previous performance, and then set a specific level of expectations for achievement as discussed by Rist (1977), the frequency of homework assignments would likely vary between schools even under the same national curriculum. It is hypothesized that, when teachers have high expectations for academic achievement, they frequently assign homework to encourage students to study outside of school. Thus, the degree of teachers' expectations for student achievement should predict the frequency of homework assignments even when school-SES is controlled--a higher degree of teachers' expectations for student achievement should positively relate to a higher frequency of homework assignments at the school level.

Hypothesis 3: The degree of teachers' expectations for student achievement and the frequency of homework assignments are associated with students' academic performance.

This study hypothesizes the association between the two school factors and students' achievement; differences in teachers' expectations and instructional approach at the school level partly explain the achievement gap between schools, as U.S. studies (e.g., Lee \& Loeb, 2000) have suggested that there exist school-effects of teachers' expectations on student learning. 
Hypothesis 4: Disparities between schools become wider at junior high schools, compared with those in elementary education.

Since Japanese compulsory education, especially elementary education, was highly regarded in the past (e.g., Cummings, 1980), elementary schools may still function as a great equalizer. In addition, while over $50 \%$ of eighth graders attend juku (shadow education institutions) lessons, only $26.2 \%$ of fourth grade students do so (MEXT, 2008). As a smaller percentage of primary school students receives supplementary education outside of school that is likely to improve their academic skills, the achievement gap between schools is likely to be smaller in elementary education.

\section{Method}

\subsection{Data}

To investigate the research questions, this study uses TIMSS 2007 and 2011 implemented by the International Association for the Evaluation of Educational Achievement (hereafter, IEA). Fourth grade students tested in 2007 reached eighth grade in 2011; the same age cohort was randomly selected through two-stage sampling processes in each year, respectively. Schools were randomly sampled, and afterward another random sampling was carried out to select one class from each school (e.g., National Institute for Educational Policy Research, 2013). These nationally representative datasets include 4,487 fourth grade students in 148 elementary schools and 4,414 eight graders in 138 junior high schools.

It should be noted that the test was administrated in March, which is the end of the Japanese academic year. This means that eighth grade students have about eleven months before taking high-stakes entrance examinations for high schools. As Japanese high schools are hierarchically ranked and its school ranking shapes students' academic trajectories (e.g., Kariya 2011), eighth grade students' academic performance in March is extremely important.

\subsection{Variables}

This study includes three variables for student-level and five indicators for school-level used to analyze both fourth and eighth grade-datasets. In addition to these variables, a schoollevel variable that shows types of school sectors (public or private/national) was created for the eighth grade data.

\section{Student level variables}

Student Cultural Capital (Student CC, hereafter). Fourth and eighth grade students reported the number of books they have at home. They were also asked to answer if they have specific home possessions (e.g., an Internet connection) in their home. Students' responses to nine (fourth graders) and eleven (eighth graders) home possessions were added to create an index of "home possessions" for each grade, respectively. ${ }^{2}$ Subsequently, a principal component analysis was carried out with the number of books and "home possessions" to create Student CC for each grade. ${ }^{3}$ This variable, which represents a volume of objectified cultural capital (Bourdieu, 1986) at home, is included in this study as a proxy of SES.

Student Performance. This study utilizes five plausible values (PVs) in mathematics to represent student academic performance: ASMMAT01-05 for the fourth grade and 
BSMMAT01-05 for the eighth grade. Mathematics was selected for analyses as the core subject instead of science, which is the other subject that TIMSS tests. Each PV was included in every analysis, and results of the analyses were averaged, while student and school weights were applied.

Female. Female students are shown as 1, and male students are indicated as 0.

\section{School level variables}

School CC. At each school, Student CC was aggregated at the school level. This variable indicates school composition (e.g., Raudenbush \& Bryk, 2002) of Student CC. Studies analyzing international data (i.e., TIMSS and PISA) also use averaged student SES, or CC, as school SES (CC) (e.g., Sudo, 2013). To help interpret results, this variable was standardized $($ mean $=0$, standard deviation $=1)$.

School Performance. At each school, each PV was averaged to represent a school's performance. This method of coding is conventional using international datasets (e.g., Knipprath, 2010).

Private/National. By using explicit stratum code in the data of eighth graders, private/ national junior high schools are shown as 1 , and public schools are indicated as 0 . This should be included in analyses, as students at private junior high schools located in urban areas seem to obtain higher academic performance (Taki 2012); without this variable, betweenschool differences would likely be overestimated. No data is provided for elementary schools regarding school sectors.

Large City/Urban. Schools located in large cities were coded as 1 for the fourth grade, and those in urban areas were shown as 1 for the eighth grade level. All other cities/non-urban areas are indicated as $0 .{ }^{4}$

Teacher Expectation. As an indicator of teachers' expectations for student achievement (performance), the study uses school principals' responses to the School Questionnaire administered by IEA for fourth grade in 2007 and for eighth grade in 2011(2007a, p.5; 2011a, p.6). Namely, to the question "How would you characterize each of the following within your school?" with “d) Teachers' expectations for student achievement," school principals' responses were recoded as follows: "Very high" (3), "high" (2), "medium" (1), and "low" (0), as there was no response to "very low" at both grade levels. 5

Homework. Yamada (2009) includes the frequency of homework assignments as a classroom-factor in his analyses, and this study similarly creates a "homework" variable by using students' responses to Q14 of the Student Questionnaire by IEA (2007b, p.15) for fourth grade, and Q20 (IEA, 2011b, p.19) for eighth grade: "How often does your teacher give you homework in mathematics?" Students of both grades selected one of the following four responses: "Every day," "3 or 4 times a week," "1 or 2 times a week," "less than once a week" and "never." These were recoded and then averaged at each school to represent the frequency of homework assignments that students perceive at each school. ${ }^{6}$ It should be noted that this variable indicates only one aspect of teachers' educational intervention that school $\mathrm{CC}$ and teachers' expectations for student achievement would affect. 
Table 1 Descriptive statistics for continuous variables

\begin{tabular}{lccccccc}
\hline $\mathbf{4}^{\text {th }}$ & $\mathrm{N}$ & Min & Max & Mean & SD & Skewness & Kurtosis \\
\hline School Cultural Capital (CC) & 147 & -3.018 & 2.283 & 0 & 1 & -0.172 & -0.086 \\
School Performance & 147 & -3.130 & 2.438 & 0 & 1 & -0.337 & 1.771 \\
Homework & 147 & -3.809 & 1.496 & 0 & 1 & -0.911 & 1.483 \\
Student CC & 4227 & -3.291 & 2.295 & 0 & 1 & -0.058 & -0.336 \\
Student Performance & 4227 & 282.472 & 835.122 & 573.411 & 74.208 & -0.235 & 0.233 \\
\hline 8th & $\mathrm{N}$ & Min & Max & Mean & SD & Skewness & Kurtosis \\
\hline School CC & 136 & -2.290 & 2.873 & 0 & 1 & -0.376 & 0.189 \\
School Performance & 136 & -2.173 & 4.168 & 0 & 1 & 0.877 & 2.808 \\
Homework & 136 & -1.720 & 2.567 & 0 & 1 & 0.702 & -0.432 \\
Student CC & 4270 & -3.506 & 2.193 & 0 & 1 & -0.114 & -0.268 \\
Student Performance & 4270 & 161.624 & 855.862 & 570.246 & 83.625 & -0.277 & 0.154 \\
\hline
\end{tabular}

\section{Analysis}

First, logistic (for fourth grade) and ordinal (for eighth grade) regression analyses were carried out with each school-level data to test the relationship between school-CC and teachers' expectations. ${ }^{7}$ Second, a multiple regression analysis was conducted to assess the relationship between teachers' expectations for student achievement and the frequency of homework assignments at each grade-level. Finally, a multilevel regression analysis was carried out to empirically investigate whether or not teachers' expectations and teaching approach can explain the achievement gap between schools for each grade. ${ }^{8}$

Because of space limitations, only the final models' results are presented in this study. The final analyses were carried out with random intercept and slope models. The variation in intercepts' levels was estimated to reflect differences between schools in Student Performance, and Student CC-slope differs between schools, meaning that Student CC effect on Student Performance varies between schools. Female students' slope was fixed as it appeared to be insignificant, indicating that the effect of gender on Student Performance does not differ between schools. ${ }^{9}$

\section{Results}

\subsection{Descriptive statistics}

\section{Continuous variables}

Table 1 presents descriptive statistics for continuous variables for each grade level. ${ }^{10}$ Examining each grade's standard deviation (hereafter, SD) in Student Performance, we can observe that the achievement gap between students of the same cohort widened (from 74.208 to 83.625) during the four years. In addition to the data in this table, intra-class correlation (ICC) was calculated to discern between-school differences in Student Performance: 0.083 for fourth grade and 0.127 for eighth grade. This means that $8.3 \%$ and $12.7 \%$ of the differences in Student Performance are between schools, and that disparities in Student Performance (the achievement gap between schools) had increased during the four years. 
Table 2 Frequencies for categorical variables

\begin{tabular}{|c|c|c|c|c|c|}
\hline 4th & $\mathrm{N}$ & $\%$ & 8th & $\mathrm{N}$ & $\%$ \\
\hline City size & & & Type & & \\
\hline Large City (1) & 33 & 22.4 & Private/National schools (1) & 11 & 8.1 \\
\hline Others $(0)$ & 114 & 77.6 & Public schools $(0)$ & 125 & 91.9 \\
\hline Teacher Expectation & & & Location & & \\
\hline Low $(0)$ & 3 & 2.0 & Urban area (1) & 21 & 15.4 \\
\hline Medium (1) & 58 & 39.5 & Other areas $(0)$ & 115 & 84.6 \\
\hline High (2) & 81 & 55.1 & Teacher Expectation & & \\
\hline Very high (3) & 5 & 3.4 & Low $(0)$ & 8 & 5.9 \\
\hline Recoded Teacher Expectation & & & Medium (1) & 47 & 34.6 \\
\hline Low and Medium (0) & 61 & 41.5 & High (2) & 70 & 51.5 \\
\hline High and Very high (1) & 86 & 58.5 & Very high (3) & 11 & 8.1 \\
\hline Gender & & & Gender & & \\
\hline Female (1) & 2101 & 49.7 & Female (1) & 2129 & 49.9 \\
\hline Male $(0)$ & 2126 & 50.3 & Male (0) & 2141 & 50.1 \\
\hline
\end{tabular}

\section{Categorical variables}

Table 2 shows frequencies for categorical and ordinal variables. ${ }^{11}$ At the fourth grade level, there are two indicators of teachers' expectations for student achievement: Teacher Expectation and Recoded Teacher Expectation. Since (1) the numbers of schools placing within "low" and "very high" categories are few, and (2) Student Performance (five PVs) does not consistently increase over the categories (from "low" to "very high") of the Teacher Expectation variable, it was recoded into Recorded Teacher Expectation and then included in the analyses.

\subsection{Predicting the degree of teachers' expectations for student achievement}

The left side of Table 3 indicates results from the school-level (single level) logistic regression analysis with the fourth grade data. The dependent variable is Recoded Teacher Expectation (0 or 1). Meanwhile, the right side of the table shows findings with the eighth grade data: results of the school-level ordinal regression analysis whose dependent variable is Teacher Expectation ranging from 0 to $3 .^{12}$ These findings basically support the first hypothesis; for both grade levels, while its effect is not strong, higher CC-schools tend to have a higher degree of teachers' expectations for student achievement at the school level, even when city size, School Performance and Private/National (for eighth grade) are controlled. Also, higher performing schools are more likely to have a higher degree of teachers' expectations for eighth grade. Unexpectedly, School Performance is negatively associated with the degree of teachers' expectations for student achievement in fourth grade; teachers' expectations are higher at lower performing schools. In addition to these findings, private and national junior high schools tend to have a higher degree of teachers' expectations for student achievement. It should be highlighted that, according to Cox \& Snell/Nagelkerke R Square, the model of the eighth grade level has more explanatory power, compared with that of the fourth grade level.

\subsection{Predicting the frequency of homework assignments}

To test whether the second hypothesis is empirically supported, a school level multiple regression analysis was carried out for each grade. According to results of the analyses shown 
Table 3 Predicting the degree of teacher expectation

\begin{tabular}{|c|c|c|c|c|c|c|c|c|}
\hline 4th $/ \mathrm{N}=147$ & \multicolumn{2}{|l|}{ Estimates } & Std. Error & $\operatorname{Exp}(B)$ & 8 th $/ \mathrm{N}=136$ & \multicolumn{2}{|l|}{ Estimates } & \multirow[t]{2}{*}{ Std. Error } \\
\hline Constant & 0.377 & $* * *$ & 0.017 & 1.458 & Threshold & & & \\
\hline School CC & 0.500 & $* * *$ & 0.018 & 1.650 & {$[$ Expectation $=0]$} & -1.897 & $* * *$ & 0.105 \\
\hline Sch.Performance & -0.316 & $* * *$ & 0.018 & 0.731 & {$[$ Expectation $=1]$} & 0.231 & $*$ & 0.105 \\
\hline \multirow[t]{5}{*}{ Large City (1) } & -0.220 & $* * *$ & 0.036 & 0.803 & {$[$ Expectation $=2]$} & 3.729 & $* * *$ & 0.109 \\
\hline & & & & & School CC & 0.057 & $* * *$ & 0.023 \\
\hline & & & & & Sch. Performance & 0.962 & $* *$ & 0.028 \\
\hline & & & & & Urban (1) & -0.977 & $* * *$ & 0.063 \\
\hline & & & & & Private/National (1) & 0.294 & $* * *$ & 0.097 \\
\hline \multicolumn{2}{|l|}{2 Log Likelihood } & \multicolumn{2}{|c|}{25530.908} & & 2 Log Likelihood & \multicolumn{2}{|c|}{21521.466} & \\
\hline \multicolumn{2}{|l|}{ Cox \& Snell R Square } & \multicolumn{2}{|c|}{0.047} & & Cox \& Snell R Square & \multicolumn{2}{|c|}{0.210} & \\
\hline \multicolumn{2}{|l|}{ Nagelkerke R Square } & \multicolumn{2}{|c|}{0.062} & & Nagelkerke R Square & \multicolumn{2}{|c|}{0.235} & \\
\hline
\end{tabular}

$\dagger \mathrm{p}<.10, * \mathrm{p}<.05, * * \mathrm{p}<.01, * * * \mathrm{p}<.001$.

Table 4 Predicting the frequency of homework

\begin{tabular}{|c|c|c|c|c|c|c|c|}
\hline \multirow{2}{*}{$\begin{array}{l}\text { 4th/ } / \mathbf{N}=147 \\
\text { Constant }\end{array}$} & \multicolumn{2}{|c|}{$\begin{array}{c}\text { Unstandardized } \\
\text { Coefficients }\end{array}$} & \multirow{2}{*}{$\begin{array}{c}\text { Std. Error } \\
0.012\end{array}$} & \multirow{2}{*}{$\begin{array}{l}\text { 8th/ } / \mathbf{N}=136 \\
\text { Constant }\end{array}$} & \multicolumn{2}{|c|}{$\begin{array}{c}\text { Unstandardized } \\
\text { Coefficients }\end{array}$} & \multirow{2}{*}{$\begin{array}{c}\text { Std. Error } \\
0.022\end{array}$} \\
\hline & 0.185 & $* * *$ & & & -0.172 & $* * *$ & \\
\hline School CC & 0.177 & $* * *$ & 0.008 & School CC & 0.119 & $* * *$ & 0.011 \\
\hline School Performance & 0.003 & & 0.008 & School Performance & 0.126 & $* * *$ & 0.013 \\
\hline Teacher Expectation & -0.144 & $* * *$ & 0.014 & Teacher Expectation & 0.137 & $* * *$ & 0.013 \\
\hline \multirow[t]{2}{*}{ Large City (1) } & -0.502 & $* * *$ & 0.017 & Urban (1) & -0.894 & $* * *$ & 0.029 \\
\hline & & & & Private/National (1) & 0.749 & $* * *$ & 0.042 \\
\hline Adjusted R square & & 0.059 & & Adjusted R square & & 0.203 & \\
\hline
\end{tabular}

$\dagger \mathrm{p}<.10, * \mathrm{p}<.05, * * \mathrm{p}<.01, * * * \mathrm{p}<.001$.

in Table 4, contrary to our expectations, teachers at schools with a higher degree of teachers' expectations for student achievement are less likely to assign math homework to fourth grade students, and School Performance is not significantly related to the frequency of homework. Turning attention to the eighth grade level, as hypothesized, School CC and Teacher Expectation predict the frequency of homework assignments, even when Private/National is controlled. Teachers at schools with a higher CC composition of students and a higher degree of teachers' expectations for student achievement tend to assign math homework more frequently. Additionally, higher performing junior high schools are more likely to give homework to eighth graders. Teachers at private and national schools also tend to give assignments to their eighth grade students more often. Again, the eighth grade model has more explanatory power compared with that of fourth grade. Overall, these results empirically support the second hypothesis only for the eighth grade level.

\subsection{Factors contributing to the achievement gap between schools}

To test the third hypothesis, multilevel regression analyses were conducted with Teacher Expectation (Recoded Teacher Expectations for fourth grade) and Homework for each grade, respectively. ${ }^{13}$ The left side of Table 5 presents results of the multilevel regression analysis, predicting fourth grade students' academic achievement (Student Performance). Recoded 
Table 5 Factors contributing to the achievement gap between schools

\begin{tabular}{|c|c|c|c|c|c|c|c|}
\hline 4 th & Coefficient & & Std. Error & 8 th & Coefficient & & Std. Error \\
\hline School Level $(N=147)$ & & & & School Level $(N=136)$ & & & \\
\hline Intercept & 573.219 & $* * *$ & 3.526 & Intercept & 552.577 & $* * *$ & 5.537 \\
\hline School CC & 6.582 & $* * *$ & 2.332 & School CC & 3.707 & & 4.108 \\
\hline Large City (1) & 1.291 & $*$ & 6.350 & Urban (1) & 13.838 & $* *$ & 5.617 \\
\hline Re-Teacher Expectation (1) & -4.699 & & 4.573 & Teacher Expectation (0 to 3 ) & 9.025 & $* * *$ & 2.886 \\
\hline \multirow[t]{2}{*}{ Homework } & -0.292 & & 2.615 & Homework & 2.122 & & 2.644 \\
\hline & & & & Private/National (1) & 41.134 & $* * *$ & 12.811 \\
\hline Student Level $(N=4227)$ & & & & Student Level $(N=4270)$ & & & \\
\hline Student CC & 23.831 & $* * *$ & 1.686 & Student CC & 21.538 & $* * *$ & 2.567 \\
\hline Female (1) & 0.139 & & 2.397 & Female (1) & -5.008 & & 3.108 \\
\hline Random Effect & SD & & $\mathrm{VC}$ & Random Effect & SD & & $\mathrm{VC}$ \\
\hline Intercept & 16.567 & $* * *$ & 274.724 & Intercept & 15.277 & $* * *$ & 234.083 \\
\hline Student CC slope & 7.480 & $* * *$ & 56.120 & Student CC slope & 10.282 & $* * *$ & 107.234 \\
\hline Level-1 & 67.518 & $* * *$ & 4559.286 & Level-1 & 72.026 & $* * *$ & 5188.092 \\
\hline Deviance & 47817.871 & & & Deviance & 48833.839 & & \\
\hline
\end{tabular}

$\dagger \mathrm{p}<.10, * \mathrm{p}<.05, * * \mathrm{p}<.01, * * * \mathrm{p}<.001 . / \mathrm{SD}=$ Standard Deviation, $\mathrm{VC}=$ Variance Component

Teacher Expectation (indicated as Re-Teacher Expectation in the table) and Homework appear to be insignificant, showing that these two factors do not explain the achievement gap between schools, while School CC significantly relates to Student Performance. To discover whether the trend persists when students attend junior high schools, the same analysis was applied for the eighth grade level of the cohort. The right side of the table indicates that the same cohort's Student Performance is shaped by teachers' expectations for student achievement, but not by the frequency of homework assignments. More specifically, students who attend junior high schools that have a higher degree of teachers' expectations for student achievement demonstrate higher academic performance, even though the frequency of homework assignments is not associated with students' performance in math. Since Teacher Expectation ranges from 0 (low) to 3 (very high), students at schools with "very high"-Teacher Expectation have 27.075 points (9.025 x 3) when compared to those at schools with "low"-Teacher Expectation, holding other variables constant. Also, as expected, attending private and national schools significantly relates to Student Performance; eighth grade students who go to private or national schools would have 41.134 points higher than those who attend public schools.

\section{Discussion}

The literature that addresses disparities between schools in Japanese compulsory education has mainly focused on differences between types of schools (i.e., public schools, compared with private counterparts). It is indeed important to pay attention to the differences between the school sectors, since "rich flight" (Fujita, 2010) is observed, and only some families can afford to prepare and enroll their students in private education (e.g., Kataoka, 2009; Mochizuki, 2011). These choices that are available to advantaged families seem to be how the achievement gap persists and even grows: a mechanism of creating, maintaining, and widening inequality in 
compulsory education. Meanwhile, this study focuses on between-school disparities in general by controlling for private/national schools, as most students attend neighboring public schools. The study's findings indicate, despite efforts to minimize regional differences, e.g., progressive public investment in compulsory education (Kariya, 2009), the achievement gap between schools continues to widen within the compulsory public education system.

The findings of this study basically reveal between-school disparities in terms of school-CC, the degree of teachers' expectations for student achievement, the frequency of homework assignments and academic achievement at the both grade-levels of the same cohort, while disparities between schools at the eighth grade level are wider than those in fourth grade. ${ }^{14}$ First, School CC predicts the degree of teachers' expectations for student achievement; students' aggregated CC (a composition of individual CC) appears to influence the degree of teachers' expectations for student achievement, even when School Performance and Private/National (for eighth grade) are controlled. This result parallels with that found in the U.S. (e.g.,Ready \& Wright, 2011) as well as in Japan (Nishimoto, 2001). Since the degree of teachers' expectations does not have an effect upon changing school $\mathrm{CC}$, the causal direction of the relation is that school CC shapes the degree of teachers' expectations. This finding could be interpreted as a consequence of labeling (e.g., Rist, 1977). It seems that teachers consciously or subconsciously determine a certain level of expectations for student achievement based on a composition of student-CC. Second, the degree of teachers' expectations significantly relates to how often teachers give homework in mathematics to their eighth grade students, when school-CC and Private/National are controlled. ${ }^{15}$ In contrast, the degree of teachers' expectations for student achievement is negatively related to the frequency of homework assignments in fourth grade; teachers at the fourth grade level are more likely to assign homework to students when the degree of their expectations is low. This is somewhat consistent with the negative relationship between the degree of teachers' expectations for student achievement and school performance shown on the left side of Table 3. Fourth grade-teachers seem to set higher expectations when school performance is relatively low, and these teachers give homework to their students more frequently when they have low expectations. Teachers of the fourth grade may make efforts to counteract the difficulties (i.e., lower school performance and their own degree of expectations for student achievement), while school CC still positively correlates to the degree of teachers' expectations and the frequency of assigning homework.

This study also found that the degree of teachers' expectations is associated with eighth grade students' academic achievement, which seems to be consistent with the literature (e.g., Lee and Loeb, 2000), while no such relationship was found at the fourth grade, and the frequency of homework assignments was not found to be related to either fourth- or eighth- grade students' math performance. ${ }^{16}$ If we consider all the findings in aggregate, the study provides some empirical evidence for how and when disparities between schools may emerge, persist and widen in Japanese compulsory education. In eighth grade, there are gaps in teachers' expectations that exist between schools, which partly explains the achievement gap between schools at the lower secondary education, suggesting that between-school disparities emerge and widen sometime between the fourth and eighth-grade levels. 


\section{Implications}

While every hypothesis was not supported, this empirical investigation still provides evidence of disparities in CC, teachers' expectations/approach and achievement between schools by using the same cohort's nationally representative data of fourth and eighth-grade levels in Japan. The results appear to indicate that the disparities increase during the four years, and between-school disparities become greater at the end of the eighth-grade level. ${ }^{17}$ It should be strongly noted that the tested eighth graders had less than one year before they take the high-stakes high school entrance examinations. The reality is that grades in ninth grade likely determine which high school a student will attend (e.g., Fujihara 2012) and high school rank plays a role in how many hours students study outside of school (e.g., Kariya 2013, Matsuoka 2013) as well as the results of college admissions (e.g., Kariya 2011). Given these conditions, the degree of teachers' expectations for student achievement in relation to students' math achievement at the end of the eighth grade level may have long-term effects on students' academic trajectories. ${ }^{18}$ If neo-liberal policies such as school choice and voucher programs are put into effect, the disparities of students' SES between schools would likely become greater, and teachers' expectations and instructional approaches in eighth grade would become more differentiated. This could lead to teachers' expectations and educational interventions having more influence on students performance.

Due to the fact that teachers' expectations of early elementary-aged children have long term effects (e.g., Sorhagen 2013), the findings of this study regarding the relationship between School CC and the degree of teachers' expectations for student achievement in fourth grade questions whether the system still imparts equality as praised by U.S. researchers in the past (e.g., Cummings 1980). Additionally, the study demonstrates that teachers at lower performing elementary schools have a higher level of expectations; teachers may not engage in labeling fourth graders based on their perceptible academic performance. From this result, it could be argued that Japanese elementary schools still function as a great equalizer. Meanwhile, School CC, School Performance and Private/National are associated with the degree of teachers' expectations in eighth grade. In other words, teachers seem to label junior high school students based on their social class and perceived academic performance. It should also be noted that the relationship between Private/National and Teachers' Expectation may explain why Kariya (2011) finds that those attending private schools tend to gain admission to competitive universities, since these students are exposed to a higher degree of teachers' expectations for student achievement even at the eighth grade level. ${ }^{19}$ All of these findings indicate that especially for eighth grade there is a need to implement policies that minimize disparities in the degree of teachers' expectations, the frequency of homework assignments, and student achievement in lower secondary education. Future studies are needed to identify factors (e.g., the number of teachers, teacher training) that would help to narrow the between-school disparities that are revealed in this study.

\section{Acknowledgement}

This work was supported by JSPS KAKENHI Grant Number 24830009.

\section{Notes}

1. Kariya (2009), using national surveys of academic performance in 1962 and 2007, found a high correlation between income and student achievement at the prefectural level in 1962, and this rela- 
tionship almost vanished in 2007, even though the relationship between a high percentage of households in poverty and lower academic performance remains. While these analyses were carried out at the prefectural level, this study focuses on between-school differences.

2. The items used are AS4GTH01-09 ( $4^{\text {th }}$ grade) and BSBG05A-K ( $8^{\text {th }}$ grade).

3. Eighth grade students reported their parents' educational background, but many claimed "I don't know" about their father's background (25.8\% of students) or mothers' background $(33.3 \%)$. To avoid having large percentages of missing values that would likely produce a bias, parents' educational backgrounds were not included in this study. It should be noted that ad-hoc analyses regarding this issue were carried out, and the results with or without parental educational backgrounds in Student Cultural Capital were almost identical.

4. These were based on school principals' responses; "Urban-Densely populated" is indicated as Urban (1) for the eighth grade, while "Large City" for the fourth grade means that schools are located in a city with a population of more than 500,000 people.

5. Since teachers were asked to answer the same question, all analyses were carried out with teacher-reported variables as well. Results using teacher-reported variables are essentially identical with those that were reported by school principals.

6. Teachers were also asked to report how often they usually assign math homework to their students. Their responses were also coded and used in the analyses, but these results do not differ between student-reported averaged frequency of homework and teacher-reported frequency. The study presents results of the analyses with student-reported averaged frequency of homework assignments, in order to have a consistent variable across the sampled schools. More specifically, more than one teacher is in charge of teaching math to some of the sampled classes (one class per school). When two or more teachers co-teach a class, each teacher's role may be different (e.g., one teacher does not assign math homework as the other teacher assumes the role of assigning homework to every student in the class, or a class may be divided into two groups, and different frequencies of homework might be assigned by different teachers). This makes it difficult to comprehend results of the analyses. Since it is unable to identify each teacher's role in teaching one randomly-selected class at each sampled school, student-reported averaged frequency of homework was used. This continuous variable describes detailed differences between schools. And again, as the results are quite similar even when the teacher-reported variable was used, the results derived in this study are thought to be valid.

7. Correlation analyses were carried out with each data set prior to the main analyses. Due to space limitations, the results are not included in this paper. As hypothesized, School CC significantly correlates to School Performance, Teacher Expectation and Frequency of Homework at each grade level.

8. HLM 7.01 was used for multilevel analyses. The following model presents an instance of multilevel modeling used to analyze the fourth grade-data: Level-1 (Student level) Model: Student Performance $(\mathrm{PVs}) \mathrm{ij}=\beta 0 \mathrm{j}+\beta 1 \mathrm{j}($ Student $\mathrm{CC} \mathrm{ij})+\beta 2 \mathrm{j}($ Female $\mathrm{ij})+$ rij Level-2 (School level) Model: $\beta 0 \mathrm{j}=\gamma 00+\gamma 01($ School CC j $)+\gamma 02($ Large City $\mathrm{j})+\gamma 03($ Re-Teacher Expectation $\mathrm{j})+\gamma 04$ (Homework $\mathrm{j})+\mathrm{u} 0 \mathrm{j}, \beta 1 \mathrm{j}=\gamma 10+\mathrm{u} 1 \mathrm{j}, \beta 2 \mathrm{j}=\gamma 20$

9. No school-level variable was found that significantly relates to Student CC-slope. Student CC's effect on Student Performance varies between schools, but no reason was found for it.

10. Each weight (student and school) was applied in these descriptive statistics. All continuous variables expect that Student Performance were standardized to help interpret results. Only cases used for all analyses in this study are included. Due to lack of data, cases are missing for 260 students $(5.8 \%)$ and one school $(0.7 \%)$ of the fourth grade level and 144 students $(3.3 \%)$ and two schools $(1.5 \%)$ of the eighth grade level.

11. To show the original distribution of each variable, these frequencies are not weighted. Valid percentages are shown in the table.

12. Since the number of schools is relatively small, the results should be interpreted with caution in this section. As for the ordinal model using eighth grade data, a test of parallel lines was carried out, and slope coefficients appear to differ across response categories. It should be noted that it is known 
that this test tends to reject the proportional odds assumption, especially, when a continuous variable is included in the model (Allison, 1999). This may be the case, as the study's model includes two continuous variables (i.e., School CC and School Performance) that should not be taken out from the model since they are the main interests of the study. To verify the relationships between the degree of teacher expectations for student achievement and the independent variables (i.e., School CC and School Performance), a multinomial logit model was conducted, and results do not essentially change from those obtained from the ordinal regression model; School CC and School Performance significantly relate to a higher degree of teacher expectations for student achievement.

13. As mentioned in 3.1. Data, one class was randomly selected at each sampled school, the study employs two-level (student and school-levels) analyses to clarify between-school disparities.

14. It should be noted that this study tests each relationship separately. The study does not find that the degree of teachers' expectations for student achievement and the frequency of homework assignments mediate school CC-effect. Specifically, a multilevel regression analysis without Teacher Expectation and Homework was carried out for each grade to test whether school CC is mediated by the school factors. As a result, School CC's effect became weaker with Teacher Expectation and Homework, showing that Teacher Expectation and/or Homework mediate some of School SES-effect in fourth grade, but its effect itself is very small and insignificant. Also, the effect of School $\mathrm{CC}$ does not greatly change with/without Teacher Expectation and Homework for the eighth grade level. Thus, the study does not provide solid evidence that teachers' expectations and homework mediate School CC-effect for the both grade levels. In other words, how the CC-disparity between schools is translated into student achievement is unknown within the data, and this is a limitation of the study. In summary, while the results indicate disparities between schools in respect to school $\mathrm{CC}$, the degree of teachers' expectations, the frequency of homework assignments and achievement, especially, at the eighth grade level, the study does not find empirical evidence of a set of causal mechanisms, which would be School CC influencing the degree of teachers' expectations that differentiates their instructional approach, which in turn would improve students' academic achievement. Future studies, ideally using longitudinal data, should find SES-related schools factors that contribute to the achievement gap between schools. If found, it would mean that CC (or SES) influences students' achievement through differentiated school factors (e.g., teachers' expectations and teaching approaches).

15. The frequency of homework only represents one aspect of teachers' teaching approach, and it is not a teaching method per se. Further studies need to capture various aspects of teachers' teaching methods and approaches.

16. Yamada (2009) also finds no significant relationship between the frequency of homework assignments and fifth-grade students' academic performance in national language and arithmetic. However, an often cited study by Cooper, Robinson, and Patall (2006) indicates a generally positive relationship between homework and achievement.

17. The data does not enable us to explain why the disparities become wider between the two points of time. As discussed in the last hypothesis, the high percentage of eighth-grade students attending shadow education lessons may be one of the reasons why the achievement gap increases at the school level.

18. Since TIMSS is a cross-sectional test, it is difficult to determine the causal direction of the relationship between the degree of teachers' expectations for student achievement and outcomes (five PVs in math). It is possible that the degree of teachers' expectations for student achievement shapes students' performance, while at the same time teachers' expectations is mutually influenced by the level of students' performance. If teachers' expectations change as a result of student performance, it is still considered labeling based on students' previous academic results as Rist (1977) argues. Since the majority of students depend on public schools for their education, labeling students based on their academic performance, which is influenced by student SES, needs to be avoided.

19. This tendency is based on the unequal distribution of teachers' expectations between school sectors. The degree of teacher expectations for student achievement is "high" or "very high" for all private/ national school included in the data. More concretely, $24.4 \%$ of private/national schools have "very 
high" teacher expectations, and $75.6 \%$ of them have "high" teacher expectations when school weight is applied. In contrast, only $5.5 \%$ of public schools report "very high" teacher expectations, while $50.3 \%$ of them have "high" expectations.

\section{References}

Allison, P. D. (1999). Logistic regression using the SAS system: Theory and application. Cary, NC: SAS Institute.

Bourdieu, P. (1986). The Forms of Capital. In J. G. Richardson (Ed.), Handbook of theory and research for the sociology of education. Westport, Conn.: Greenwood Press.

Condron, D. J., \& Roscigno, V. J. (2003). Disparities within: Unequal Spending and Achievement in an Urban School District. Sociology of Education, 76(1), 18-36.

Cooper, H., Robinson, J. C., \& Patall, E. A. (2006). Does homework improve academic achievement? a synthesis of research, 1987-2003. Review of Educational Research, 76(1), 1-62.

Cummings, W. K. (1980). Education and Equality in Japan: Princeton University Press.

Fujihara, S. (2012). Kokosentaku ni okeru sotaitekirisukukaihikasetsu to gakurekikakokaihikasetsu no kensho[Empirical tests of the relative risk aversion hypothesis and the downward educational mobility aversion hypothesis regarding choice of high school in Japan]. The journal of educational sociology, 91, 29-49.

Fujita, H. (2010). Whiter Japanese schooling?: Educational reforms and their impact on ability formation and educational opportunity. In J. A. Gordon, H. Fujita, T. Kariya \& G. K. LeTendre (Eds.), Challenges to Japanese education: Economics, reform, and human rights (pp. 17-53). New York: Teachers College Press.

IEA. (2007a). TIMSS2007 School Questionnaire <Grade 4>. from http://timss.bc.edu/timss2007/PDF/ T07_SchoolQ G4.pdf

IEA. (2007b). TIMSS2007 Student Questionnaire <Grade 4>. from http://timss.bc.edu/timss2007/PDF/ T07_SudentQ_G4.pdf

IEA. (2011a). TIMSS2011 School Questionnaire<Grade 8>. http://timssandpirls.bc.edu/timss2011/downloads/T11_SchQ_8.pdf

IEA. (2011b). TIMSS2011 Student Questionnaire <Grade 8>. http://timssandpirls.bc.edu/timss2011/ downloads/T11_StuQ_8.pdf

Kariya, T. (2009). Kyoiku to byodo: Taishu kyoiku shakai ha ikani seisei shitaka [Education and equality: How mass education-society emerged]. Tokyo: Chuokoron shinsha.

Kariya, T. (2011). Japanese solutions to the equity and efficiency dilemma? Secondary schools, inequity and the arrival of 'universal' higher education. Oxford Review of Education, 37(2), 241-266.

Kariya, T. (2013). Education reform and social class in Japan: the emerging incentive divide. Abingdon, Oxon: Routledge.

Kataoka, E. (2009). Kakusa shakai to shochugaku juken--juken o tsujita shakaitekiheisa, risukukaihi, ishitsuna tasha heno kanyosei [Class closeness and parental school choice--Sociological analysis concerning 'O-Juken' and junior high school examinations in Japan. Japanese Journal of Family Sociology, 21, 30-44.

Kawaguchi, T. (2009). Maruchi reberu moderu o mochiita gakko no koka no bunseki: Kokateki na gakko ni shakai teki fubyodo no kyusai ha dekirunoka [Analysis of school effects in Japan using a multilevel model: Can effective schools overcome social disadvantages?]. The journal of educational sociology, 84, 165-184.

Knipprath, H. (2010). What PISA tells us about the quality and inequality of Japanese education in mathematics and science. International Journal of Science and mathematics Education, 8(3), 389-408.

Kozol, J. (1991). Savage inequalities: Children in America's schools. New York: Crown.

Kozol, J. (2005). The shame of the nation: the restoration of apartheid schooling in America (1st ed.). New York: Crown Publishers.

Lee, V. E., \& Loeb, S. (2000). School size in Chicago elementary schools: Effects on teachers' attitudes and students' achievement. American Educational Research Journal, 37(1), 3-31. 
Lewis, C. C. (1995). Educating hearts and minds: reflections on Japanese preschool and elementary education. Cambridge; New York: Cambridge University Press.

Matsuoka, R. (2013). Tracking effect on tenth grade students' self-learning hours in Japan. Riron to hoho [Sociological Theory and Methods], 28(1), 87-106.

MEXT. (2008). Kodomo no gakkogai deno gakushukatsudo ni kansuru jittai chosa hokoku [Actual condition survey on learning activities of children outside of schools]. Retrieved August 1st, 2013, from http://www.mext.go.jp/b_menu/houdou/20/08/08080710.htm

Mochizuki, Y. (2011). Gendai nih̀n no shiritsushogakko juken: Pearentokurashi ni motozuku kyoikusembatsu no genjo [Entrance examinations of private elementary schools in modern Japan: Current status of educational selection based on parentocracy]. Tokyo: Gakujutsu Shuppankai.

National Institute for Educational Policy Research. (2013). TIMSS2011 sansu sugaku kyoiku no kokusaihikaku: Kokusai sugaku rika kyoiku dokochosa no 2011 nen chosa hokokusho [TIMSS 2011 international comparison of arithmetic/mathematics education: Investigative report on TIMSS 2011]. Tokyo: Akashi shoten.

Nishimoto, H. (2001). Kyoshi no hyoka to chugakusei no gakuryoku no kanrensei: Kaiso mondai ni hisomu kyoshi no manazashi ni chakumoku [Relationship between teacher's evaluation and student's academic achievement]. Ningenkagaku [Human science], 7, 29-42.

Oakes, J. (1985). Keeping track: how schools structure inequality. New Haven: Yale University Press.

Raudenbush, S. W., \& Bryk, A. S. (2002). Hierarchical linear models : applications and data analysis methods (2nd ed.). Newbury Park, CA: Sage.

Ready, D. D., \& Wright, D. L. (2011). Accuracy and inaccuracy in teachers' perceptions of young childrens' cognitive abilities: The role of child background and classroom context. American Educational Research Journal, 48(2), 335-360.

Rist, R. (1977). On understanding the processes of schooling: The contributions of labeling theory. In J. Karabel \& A. H. Halsey (Eds.), Power and ideology in education. New York: Oxford University Press.

Shimizu, K. (Ed.). (2009). Chikara noaru gakko no tankyu [Exploring effective schools]: Osaka daigaku shuppankai.

Sorhagen, N. S. (2013). Early teacher expectations disproportionately affect poor children's high school performance. Journal of Educational Psychology, 105(2), 465-477

Stigler, J. W., \& Hiebert, J. (1999). The teaching gap: best ideas from the world's teachers for improving education in the classroom. New York: Free Press.

Sudo, K. (2013). Gakko no kyoiku koka to kaiso [The effect of school education and social class]. Tokyo: Toyokan shuppansha.

Taki, H. (2012). Gimukyoikudankai niokeru gakuryoku to shakaikeizaitekichii no kanrenkozo: TIMSS data o mochiite[Associated structure between academic performance and socioeconomic status in compulsory education using TIMSS data]. Paper presented at the 85th Conference of the Japan Sociological Society, Sapporo.

Tsuneyoshi, R. (2001). The Japanese model of schooling: comparisons with the United States. New York: Routledge.

Yamada, T. (2009). Kakusa o shukusho suru gakkyukoka no tankyu: maruchi reberu moderu o mochiita bunseki [Exploring classroom-effects that narrow the achievement gap: An analysis using multilevel modeling]. Retrieved August 1st, 2013, from http://berd.benesse.jp/berd/center/open/report/kyoiku_ kakusa/2008/pdf/data_06.pdf 